\title{
Shock-Induced Transition of Quartz to Stishovite ${ }^{1}$
}

\author{
John D. Kuemman ${ }^{2}$ and Thomas J. Ahrens \\ Seismological Laboratory, California Institute of Technology \\ Pasadena, California 91109
}

\begin{abstract}
The transformation of quartz to stishovite has been studied by X-ray and optical examination of a series of experimentally shock-loaded specimens of a quartz-copper mixture. Shock pressures of 68 to $260 \mathrm{~kb}$ and peak temperatures of $320^{\circ}$ to $870^{\circ} \mathrm{K}$ were achieved. Stishovite was identified from quartz shock-loaded above $90 \mathrm{~kb}$; the quantity increases with increasing pressure, but is not dependent on temperature. The formation of stishovite under shock conditions appears to be intimately related to a short-range order phase.
\end{abstract}

Stishovite is a high-pressure polymorph of silicon dioxide, having the same structure as rutile and cassiterite. It is found in nature as a minute component of shocked quartz-bearing rocks associated with meteorite impact. Stishov and Popova [1961] first produced this phase in static high-pressure experiments. Shortly afterward, Chao et al. [1962] found small quantities of stishovite in the intensely shocked quartz sandstone at Meteor Crater, Arizona. Subsequent work [Chao and Littler, 1963] has demonstrated the natural occurrence of this mineral at only one other impact crater (Ries basin, Germany). In 1965 stishovite was first isolated from experimentally shocked quartz [DeCarli and Milton, 1965], although it was not possible to compare, in detail, the pressure and temperature conditions required to produce stishovite dynamically with the static results. One important objective of the present study was to determine the lowest shock pressure required to produce stishovite from quartz.

Measurements of the Hugoniot equation of state of quartz indicate that stishovite, with or without coesite, will form a major part of the phase assemblage at pressures above $140 \mathrm{~kb}$ [Wackerle, 1962; McQueen et al., 1963]. Ahrens

\footnotetext{
${ }^{1}$ Contribution 2203, Division of Geological and Planetary Sciences, California Institute of Technology, Pasadena, California.

'Permanent address: Department of Geology, University of New England, Armidale, N.S.W., Australia.
}

Copyright (C) 1973 by the American Geophysical Union. and Rosenberg [1968] indicate an increasing proportion of high-pressure polymorphs above $120 \mathrm{~kb}$. DeCarli and Milton [1965] suggested that the major proportion of stishovite at equilibrium reverts to an amorphous, or shortrange order (SRO), phase upon release from the high-pressure shock state. Our first experiments revealed no significant quantities of SRO phase coexisting with the minute fraction of stishovite recovered from shock pressures of about $180 \mathrm{~kb}$. We wish to characterize the occurrence of SRO phase in relation to stishovite formation.

The third objective of this study was to investigate the parameters likely to reflect on the quantity of stishovite produced. Factors such as temperature (both in equilibrium shock state and in postshock state), rate of cooling during shock pressure release, duration of shock, as well as the amount of pressure overdriving, were thought to be potentially effective in varying the yield of recovered stishovite. The results of this aspect of the study will help in selecting the optimum conditions for producing other high-pressure minerals in the laboratory.

\section{BASIS OF EXPERIMENTS}

The impact of a metal flyer plate, imbedded at the front of a Lexan plastic projectile, induces a shock wave in a target assembly (Figure 1). The shock state produced in the target is determined from the measured flyer-plate velocity and the Hugoniots of the target and flyerplate materials by the impedance match method [Rice et al., 1958]. In these experiments the sample consisted of a mixture of quartz and 
copper powders (quartz, $6 \%$ by weight). The pressure-volume Hugoniot for the mixture (assumed to retain no porosity) was constructed from the data for the individual components using the relation [McQueen et al., 1970]

$$
V(p)=\sum_{i=1}^{2} m_{\imath} V_{\imath}(p)
$$

where $V_{1}$ is the specific volume of the $i$ th component at pressure $p$ and $m_{t}$ is the mass fraction of this component. The assumption, implicit in Figure 2, is that the quartz and copper are both shocked to pressure-volume states along their individual Hugoniots centered at standard conditions. However, the internal energy increase of the mixture depends upon initial porosity. Before shocking, the mixture was compacted into a hard pellet using a reproducible pressure. The density of the compressed material is also reproducible. Since the sample was porous before shock loading, the appropriate Hugoniot for use in the impedance match method was calculated from the relation

$$
u=\left[p\left(V_{\infty}-V\right)\right]^{1 / 2}
$$

where $u$ is the particle velocity of the mixture, $V_{\infty}$ is the specific volume of the porous mixture at zero pressure, and $V$ is the specific volume at pressure $p$, as calculated from Figure 2 . Equation 2 amounts to the 'ideal locking' model of Linde and Schmidt [1966].

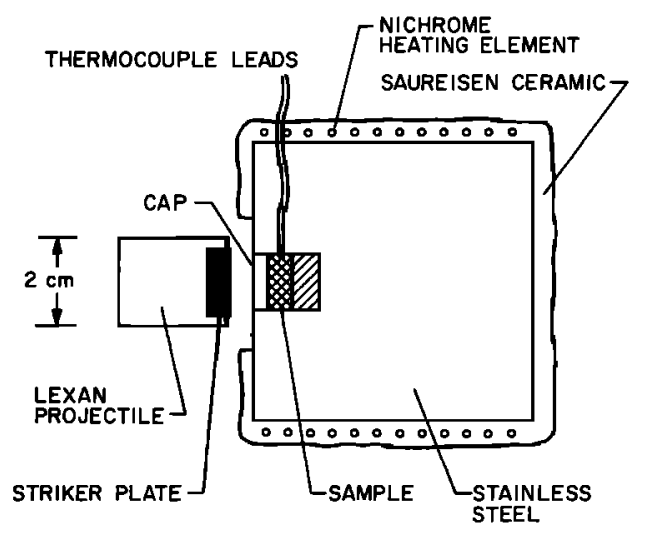

OUARTZ-COPPER MIXTURE Y/, COPPER ALONE

Fig. 1. Diagrammatic cross section of the shock recovery experiment. Projectile velocity and thermocouple voltage are recorded before impact.
Hugoniots for tungsten alloy (the usual striker plate material: $16.8 \mathrm{~g} / \mathrm{cm}^{\mathrm{a}}$ ), the copperquartz aggregate, and the stainless steel encasing the sample are shown schematically in Figure 2. Experimental data for constructing the Hugoniots shown in Figure 2 are taken from McQueen et al. [1970], Ahrens and Gaffney [1971], and Wackerle [1962].

The duration of the shock pulse was determined by the time taken for the rarefaction originating from the rear of the striker plate to pass the same point as the shock front. By calculating the velocities of shock wave and rarefaction, a time-distance plot can be constructed for one geometry [Gibbons and Ahrens, 1971]. For the 5-mm thick flyer plates used in these experiments, the shock pulse duration is about $2 \mu$ sec. There is also a reflected compression originating from the back of the sample cavity, from the nonporous denser stainless steel. This reflection will enhance the pressure in the rear of the sample cavity, and for this reason no quartz was mixed in the copper powder in this volume (see Figure 1). There should not be a significant pressure gradient in the quartz-copper portion of the target.

The use of copper mixtures has some distinct advantages. The Hugoniot of the sample mixture is closer to that of stainless steel than quartz (see Figure 2), especially when compared with porous quartz aggregates (e.g., pressed quartz powder or sandstone). This results in less perturbation of the shock front as it passes through the sample, giving more even distribution of pressure, especially at the edges, and more favorable conditions for recovery intact. In addition, higher pressures can be obtained with the same projectile velocity. Another important advantage is temperature control. Since the thermal equation of state of copper is well determined [McQueen et.al., 1970], the shock temperature can be calculated. The postshock temperature achieved in the $\mathrm{SiO}_{2}$ experiments is largely controlled by the properties of the copper. In addition, the copper conducts heat rapidly into the stainless steel block, which acts as a heat sink, quickly reducing postshock temperatures.

\section{Shock and Postshock Temperatures}

The copper-quartz mixture is relatively incompressible, and shock pressures are relatively 
modest, so that the entropy production is not great, and the shock and postshock temperatures are largely controlled by the preshock temperature. Nevertheless, it is useful to attempt to approximately calculate shock and postshock temperatures for these experiments.

If, upon shock compression the quartz fragments remain at their initial maximum grain size of 0.01 to $0.025 \mathrm{~cm}$ in diameter, thermal equilibrium with the surrounding copper matrix takes place in the order of $10^{-5}$ sec. Since the high-pressure shock duration is $2 \times 10^{-6} \mathrm{sec}$, only thermal equilibrium in the postshock state will be achieved within the copper matrix. On the other hand, if a significant number of quartz grains are crushed by the shock and the effective particle size is significantly reduced, thermal equilibrium (largely controlled by the shock state in the copper) should be achieved during passage of the stress wave. For the present calculation, the latter case is assumed. This assumption is not critical, as the postshock and shock temperatures are nearly equivalent, since the shock-induced temperature rise is largely accounted for by the irreversible work done on the sample in crushing out initial porosity.

Two estimates of shock and postshock temperatures were obtained. As a first approximation, the actual quartz content of the samples was neglected. A lower temperature was calculated by assuming that the samples were entirely copper and the density (6.45 to 6.55 $\mathrm{g} / \mathrm{cm}^{3}$ ) arose wholly from initial porosity of $27 \%$ in the copper matrix. The Hugoniot temperatures for porous aggregate were calculated using the formulas given by Ahrens [1972] and the Gruneisen parameter and temperature along the principal Hugoniot of copper reported by McQueen et al. [1970]. Slightly higher values for the shock temperatures were obtained by calculating the internal energy increase versus temperature for a pure copper sample having the same porosity as the sample $(17 \%)$. In both calculations, the shock temperatures (Table 1) were obtained by correlating the increases in internal energy for the pure copper case with the corresponding energy increase for the actual sample. The latter was obtained by constructing a porous quartz and copper Hugoniot as described in the preceding section. By calculat-

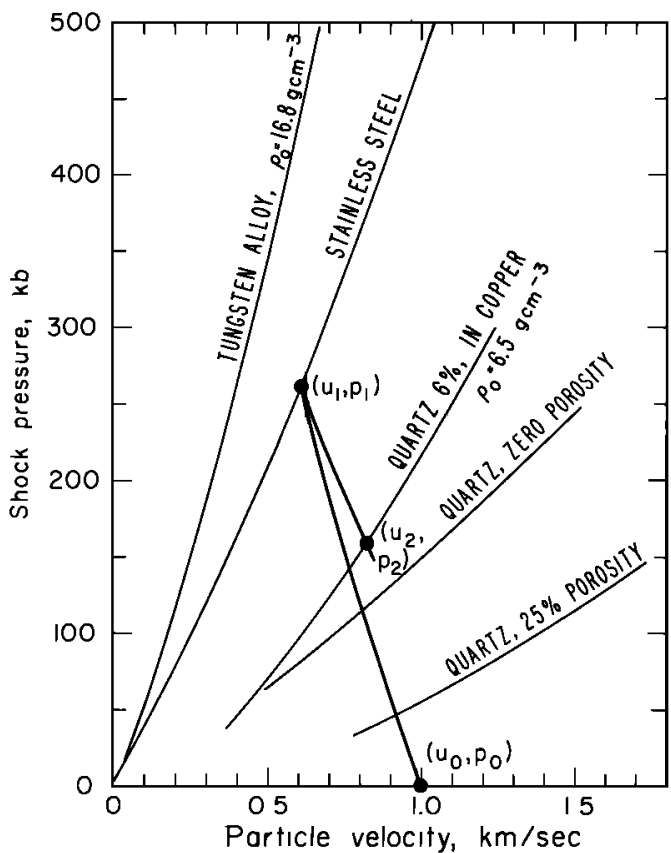

Fig. 2. Pressure-particle velocity plane indicating shock state $\left(u_{1}, p_{1}\right)$ produced by impact of flyer plate with velocity $u_{0}$ into stainless steel cap. Transmitted stress wave produces shock state in copper-quartz mixture $\left(p_{2}, u_{2}\right)$.

ing the entropy increases [Ahrens, 1972] for the two cases outlined above and comparing the entropies with thermodynamic tabulation of entropy versus temperature at standard pressure [Robie and Waldbaum, 1968], it was found that the calculated postshock temperatures differ by about $30^{\circ} \mathrm{C}$ at most from the shock temperature. The near equivalence of these temperatures occurred because shock heating was largely the result of irreversible crushing-out of the initial sample porosity.

\section{Experimental Method}

A single crystal of Brazilian quartz was crushed, and the fraction -60 to +160 mesh was mixed with pure copper powder in the proportion $6 \%$ quartz by weight. This mixture (theoretical nonporous density of $7.82 \mathrm{~g} / \mathrm{cm}^{2}$ ) was then pressed into the cavity in the stainless steel block (alloy 304) with a reproducible pressure equivalent to about $2.5 \mathrm{~kb}$. Pellets made under the same conditions have a density of 6.45 to $6.55 \mathrm{~g} / \mathrm{cm}^{8}$ or a porosity ranging from 16.2 to $17.5 \%$. A cap of stainless steel was then 
TABLE 1. Results of Recovery of Stishovite from Shocked Quartz

\begin{tabular}{|c|c|c|c|c|c|c|}
\hline $\begin{array}{l}\text { Laboratory } \\
\text { Run }\end{array}$ & $\begin{array}{l}\text { Pressure, } \\
\text { kb }\end{array}$ & $\begin{array}{c}\text { Preshock } \\
\text { Temp. } \\
\underset{{ }^{\circ} \mathrm{K}}{\text { eng }}\end{array}$ & $\begin{array}{c}\text { Calculated } \\
\text { Shock } \\
\text { Temp. } \\
{ }_{\mathrm{o}} \mathrm{K}\end{array}$ & $\begin{array}{l}\text { No. of } \\
\text { Stishovite } \\
\text { Lines }\end{array}$ & $\begin{array}{l}\text { Quality of } \\
\text { Identification }\end{array}$ & $\begin{array}{c}\text { Yield } \\
\text { Estimate }+\end{array}$ \\
\hline IPG-22 & 188 & 295 & 380 to 420 & 9 & Good & 3 \\
\hline 23 & 170 & 520 & 625 to 660 & 4 & Fair & 2 \\
\hline 24 & 160 & 295 & 363 to 395 & 5 & Fair & 2 \\
\hline 34 & 194 & 740 & 830 to 870 & 7 & Good & 3 \\
\hline 35 & 200 & 295 & 390 to 435 & 17 & Excellent & 4 \\
\hline 36 & 216 & 529 & 673 to 723 & 16 & Good & 4 \\
\hline 43 & 145 & 770 & 833 to 858 & 4 & Fair & 2 \\
\hline 44 & 90 & 770 & 806 to 818 & 1 & Equivocal & $?$ \\
\hline 45 & 90 & 295 & 328 to 340 & 4 & Fair & 1 \\
\hline 46 & 100 & 295 & 333 to 348 & 9 & Good & 2 \\
\hline 47 & 72 & 295 & 320 to 330 & None & Negative & None \\
\hline $48 *$ & 166 & 295 & 369 to 403 & $18^{\star}$ & Excellent & 5 \\
\hline 49 & 68 & 295 & 317 to 328 & None & Negative & None \\
\hline 50 & 234 & 295 & 410 to 470 & 9 & Good & 2 \\
\hline 51 & 260 & 295 & 433 to 500 & 11 & Good & 3 \\
\hline
\end{tabular}

*Fused $\mathrm{SiO}_{2}$ starting material.

ton a scale of 0 to 5 .

pressed into the copper mixture and faced off so that the front was flat. The target was shockloaded by the techniques described by Kleeman [1971] and Gibbons and Ahrens [1971]. The velocity can be measured to $\pm 1 \%$ accuracy, but uncertainty in the Hugoniots may increase the systematic error of pressure estimates to $\pm 5 \%$. However, internal precision will be rather better than this.

After shock-loading, the stainless steel cap was machined away to expose the copper-quartz mixture. The block was placed in 10\% HNO. at room temperature for 1 to 3 days, during which the copper dissolved and $\mathrm{SiO}_{2}$ was freed. Usually $100 \%$ recovery of the $\mathrm{SiO}_{2}$ was obtained $(300-400 \mathrm{mg})$. About $50 \mathrm{mg}$ of $\mathrm{SiO}_{\mathbf{2}}$ was retained for other observations, and the rest was leached in $48 \% \mathrm{HF}$ at $23^{\circ} \mathrm{C}$ for 6 hours. The acid was then diluted to less than 5\% strength and was filtered through a Millipore filter of $0.22-\mu \mathrm{m}$ hole size. In many shots the stishovite amounted to little more than a coloration on the paper and could not be scraped off.

A sample was taken from this paper by rolling a tiny ball of rubber cement $(\sim 0.2-\mathrm{mm}$ diameter) over its surface. The ball was then put on the end of a glass capillary $(\sim 100-\mu \mathrm{m}$ diameter), which was used in place of the collimator in a 57.3-mm Debye-Scherrer camera so that optimum peak to background ratios would be obtained from minute amounts of stishovite. The sample could not be rotated. An internal standard of $\mathrm{NaCl}$ was used in some exposures for calibration of film and camera.

Five runs were made at high starting temperature. The stainless steel blocks were coated with synthetic porcelain, wound with heating element wire, then insulated with more porcelain. A thermocouple was inserted in a hole drilled to just contact the sample cavity at its middepth. Chromel-alumel and copper-constantin thermocouples were used to measure temperatures up to $770^{\circ} \mathrm{K}$. These heated shots were quenched by arranging the target to fall into cold water immediately after impact.

\section{REsults}

Stishovite recovery and identification. The white plastic Millipore filter became colored after the diluted hydrofluoric acid was filtered. Runs 47 and 49 had minimal coloration, whereas higher-pressure shots were medium brown or greenish brown. The color was not evenly distributed and appeared vaguely spotty under low-power magnification. $X$ ray samples taken from the filters indicated the presence of stishovite in all but runs 47 and 49 . The number of reflections of stishovite with $\mathrm{Fe}-\mathrm{K} \alpha$ radiation is limited to 18 ( $d$ spacings greater than $1.03 \mathrm{~A})$ by the construction of the special 
collimator. Only one sample, an almost pure recovery of stishovite from run 48 , gave all 18 reflections, and on this specimen a $\mathrm{Cu}-\mathrm{K} \alpha$ exposure produced 24 lines ( $d$ spacings to $0.88 \mathrm{~A}$ ). This specimen contained sufficient stishovite to yield a satisfactory powder pattern when mounted on a rotated spindle in a normal 114.6$\mathrm{mm}$ Debye-Scherrer camera. However, certain of the weaker reflections were not found in this exposure owing to a higher background. Results of all lines measured from $\mathrm{Cu}-\mathrm{K} \boldsymbol{\alpha}$ exposure by using the modified $57.3-\mathrm{mm}$ camera and the large normal camera are shown on Table 2. The measurements of Chao et al. [1962] (see ASTM file card 15-26) are included for comparison. Unit cell dimensions calculated from the large camera are $a_{0}=4.179 \mathrm{~A}, c_{0}=2.665 \mathrm{~A}$, which are consistent with the values $a_{0}=$ $4.1790 \mathrm{~A}$ and $c_{0}=2.6649 \mathrm{~A}$ reported by Chao et al. Lines previously listed as being found only in synthetically produced stishovite were present, as were lines previously found only in natural material.

Table 1 summarizes all the data obtained after the hydrofluoric acid treatment of recovered quartz. Lines on the powder patterns were attributed to stishovite only if they did not overlap with reflections of any other impurity present. In only one case, shot 44 , was there an equivocal result. Only the most intense line was found. The position where the second most intense line should have appeared was clear of any interference by impurities, but no line was observed. In this case the identification must remain equivocal, although we are biased toward interpreting the result as a particularly low yield.

Yield estimates were made by comparing the intensities of lines on the powder patterns. Approximately equal sections of the filter paper were swept by the rubber ball during each $X$ ray sample preparation, and they were exposed to consistent $X$ radiation intensities for known durations. The scale $0-5$ is an order of magnitude scale on approximately 2 base (i.e., $2^{a-5}$ ). Visual examination suggests that yield 5 probably corresponds to no more than $100 \mu \mathrm{g}$ of stishovite and that the powder patterns from shot 48 were obtained from $\mathrm{X}$ ray specimens of the order of $1-5 \mu \mathrm{g}$. (The rubber ball is $0.1-$ to $0.2-\mathrm{mm}$ diameter and is estimated to comprise
TABLE 2. X Ray Powder Diffraction Data from Shot 48

\begin{tabular}{|c|c|c|c|c|c|c|}
\hline \multirow[b]{2}{*}{$\underset{h k l}{\operatorname{Reflect} i o n}$} & \multicolumn{2}{|c|}{$\begin{array}{c}\text { Chao et } a \text { l. } \\
{[1962]}\end{array}$} & \multicolumn{2}{|c|}{$\begin{array}{l}57.3-\mathrm{mm} \\
\text { Camera }\end{array}$} & \multicolumn{2}{|c|}{$\begin{array}{l}114.6-m m \\
\text { Camera }\end{array}$} \\
\hline & $\begin{array}{l}d, \\
\mathrm{~A}\end{array}$ & $I / I_{1}$ & $\begin{array}{l}\text { d, } \\
\mathrm{A}\end{array}$ & $I / I_{1}$ & $\begin{array}{l}d, \\
A\end{array}$ & $I / I_{1}$ \\
\hline 110 & 2.959 & 100 & 2.940 & 100 & 2.951 & 100 \\
\hline 101 & 2.246 & 18 & 2.241 & 20 & 2.244 & 20 \\
\hline 200 & 2.09 & $1 *$ & 2.082 & 5 & 2.086 & 2 \\
\hline 111 & 1.981 & 35 & 1.974 & 40 & 1.977 & 30 \\
\hline 210 & 1.870 & 14 & 1.864 & 15 & 1.866 & 10 \\
\hline 211 & 1.530 & 50 & 531 & 50 & 1.528 & 50 \\
\hline 220 & 1.478 & 18 & 1.476 & 20 & 1.476 & 15 \\
\hline 002 & 1.333 & 10 & 1.333 & 15 & 1.332 & 10 \\
\hline 310 & 1.322 & $4 t$ & 1.321 & 5 & 1.321 & 5 \\
\hline 221 & 1.291 & 2 & 1.295 & 2 & 1.291 & 2 \\
\hline 301 & 1.235 & 25 & 1.235 & 25 & 1.233 & 20 \\
\hline 112 & 1.215 & 10 & 1.216 & 15 & 1.214 & 10 \\
\hline 311 & 1.185 & 2 & 1.184 & 5 & 1.183 & 3 \\
\hline 320 & 1.159 & $8+$ & 1.158 & 2 & & \\
\hline 202 & 1.123 & $2+$ & 1.125 & 4 & 1.123 & 1 \\
\hline 212 & 1.084 & 2 & 1.086 & 5 & 1.085 & 5 \\
\hline 321 & 1.062 & 2 & 1.063 & 5 & 1.063 & 5 \\
\hline 400 & 1.045 & 2 & 1.047 & 5 & 1.045 & 8 \\
\hline 410 & 1.013 & 2 & 1.015 & 4 & 1.014 & 5 \\
\hline 222 & 0.9900 & 6 & 0.991 & 15 & 0.990 & 12 \\
\hline 330 & 0.9850 & $2+$ & 0.987 & 5 & 0.985 & 10 \\
\hline 411 & 0.9475 & 4 & 0.949 & 15 & & \\
\hline 312 & 0.9382 & 4 & 0.939 & 10 & & \\
\hline 421 & 0.8824 & 1 & 0.885 & 5 & & \\
\hline
\end{tabular}

* Observed only on synthetic material in the past. +Not observed on synthetic material in the past.

no more than $50 \%$ stishovite by volume.) Other samples have notably less stishovite, and total yield may be as low as $5 \mu \mathrm{g}$ or less. The shot using $\mathrm{SiO}_{2}$ glass as starting material produced the greatest amount of stishovite. Ignoring this run and considering only runs with quartz as starting material, we see that increasing the pressure from 90 to $220 \mathrm{~kb}$ increases the yield and that increasing the preshock temperature (and therefore also equilibrium state temperature) does not. Yield is reduced above $230 \mathrm{~kb}$.

Runs 50 and 51 also produced a phase with large $d$ spacings, at present not identified.

Optical examination of shocked quartz and silica glass. Aliquots of the sample were kept aside for optical examination. When viewed under a binocular viewer, the shocked quartz ranged from clear to turbid white. If hand picked on this basis, the clear grains gave $\mathbf{X}$ ray powder patterns with only slight loss of definition and intensity of back reflections. The turbid grains also gave quartz powder patterns, but with more pronounced loss of definition, especially in back reflections.

Grains were also immersed in oils of known refractive index and were examined with a polarizing microscope. The results of the refractive index measurements are shown in Table 3. 
TABLE 3. Optical Examination of Shocked Quartz

\begin{tabular}{|c|c|c|c|c|c|}
\hline Run & $\begin{array}{l}\text { Shock } \\
\text { Pressure, } \\
\text { kb }\end{array}$ & $\begin{array}{c}\text { Preshock } \\
\text { Temp. } \\
{ }^{\circ} \mathrm{K}\end{array}$ & $\begin{array}{c}\text { Normal } \\
\text { Quartz, } \\
\frac{\sigma}{\circ}\end{array}$ & $\begin{array}{c}\text { Refractive } \\
\text { Index Range, } \\
\omega\end{array}$ & $\begin{array}{c}\text { Separate } \\
\text { Glass, } \\
\%\end{array}$ \\
\hline 49 & 68 & 295 & 99 & 1.542 to 1.544 & \\
\hline 47 & 72 & 295 & 99 & 1.542 to 1.544 & \\
\hline 45 & 90 & 295 & 98 & 1.542 to 1.544 & \\
\hline 46 & 100 & 295 & 98 & 1542 to 1.544 & \\
\hline 24 & 160 & 295 & 95 & 1.540 to 1.544 & \\
\hline 22 & 188 & 295 & 90 & 1.538 to 1.544 & \\
\hline 50 & 234 & 295 & 70 & 1.510 to 1.544 & 5 \\
\hline 51 & 260 & 295 & 60 & 1.496 to 1.544 & 20 \\
\hline 44 & 90 & 770 & 80 & 1.540 to 1.544 & \\
\hline 23 & 170 & 520 & 95 & 1.538 to 1.544 & \\
\hline 36 & 216 & 520 & 60 & 1.516 to 1.544 & 2 \\
\hline 34 & 194 & 740 & 60 & 1.530 to 1.544 & \\
\hline $48^{*}$ & 166 & 295 & $*$ & 1.459 to 1.530 & * \\
\hline
\end{tabular}

*Fused $\mathrm{SiO}_{2}$ starting material.

Optical examination with plane-polarized light also shows a range of shock effects within each shocked sample. A large proportion of grains are clear and, although some cracking and undulose extinction are observed, show little evidence of shock loading. A variable proportion of grains are cloudy to varying degrees and have lower refractive indices. Table 3 shows proportions of quartz with unchanged and lower refractive indexes. The total range of $\omega$ refractive index is shown and the proportion remaining at $\omega=1.544$. The data are consistent with those of Hörz [1968]. Planar features were observed in most samples shock loaded to more than $140 \mathrm{~kb}$. They were rare below $210 \mathrm{~kb}$, but no more than $1 \%$ or $2 \%$ of the grains had planar features in any sample.

The three shots above $210 \mathrm{~kb}$ produced a separate glass phase, that is, where whole grains were essentially isotropic. The refractive indices are higher than for fused silica $(\eta=1.459$ [Gibbons and Ahrens, 1971]). (This shockformed glass is the same as is variously termed 'thetomorphic' or 'diaplectic.')

Data from the shot with fused silica are also shown in Table 3 . The range of refractive index is consistent with measurements reported by Gibbons and Ahrens [1971].

\section{Discussion}

Figure 3 illustrates the results of stishovite recovery in the pressure-temperature plane. Shock temperatures are plotted, although postshock temperatures are probably not more than $30^{\circ} \mathrm{C}$ lower. Stishovite is found at shock pressures of $90 \mathrm{~kb}$ and greater. An equivocal identification resulted from shot $44\left(90 \mathrm{~kb},-825^{\circ} \mathrm{K}\right.$ shock temperature). This is at or slightly below the thermodynamically predicted pressure. At $350^{\circ} \mathrm{K}$ a similar point should be $73 \mathrm{~kb}$.

The most significant result is that the formation of stishovite from quartz is consistent with the calculated quartz-stishovite boundary of Holm et al. [1967] and the experimental coesitestishovite phase line of Ostrovsky [1967] and Akimoto and Syono [1971] (see Figure 3). The data are also consistent with the $75-\mathrm{kb}$ value inferred by Ahrens and Gregson [1964] from study of the $P-V$ Hugoniot of Coconino sandstone. Increasing yields of stishovite were recovered as pressures increased from $90 \mathrm{~kb}$, until shots 50 and 51 actually produced less, with the accompaniment of whole grains of shock-formed glass. Temperature does not affect yield. (An increased yield with increasing temperature may have indicated that the rate of transformation to stishovite is kinetically controlled.)

The increased yield of stishovite with increasing pressure is accompanied by a greater proportion of quartz with diminished refractive index. These lower refractive indices may well be caused by submicroscopic inelusions of glass in the quartz. In this case, the increased yield of stishovite is accompanied by increasing quantities of submicroscopic glass. This association may be an important indication of the way stishovite forms during shock loading. This submicroscopic glass is the zero-pressure equivalent of either a crystalline phase, such as stishovite, or collapsed quartz of SRO. All shots achieved temperatures of less than $900^{\circ} \mathrm{K}$, and

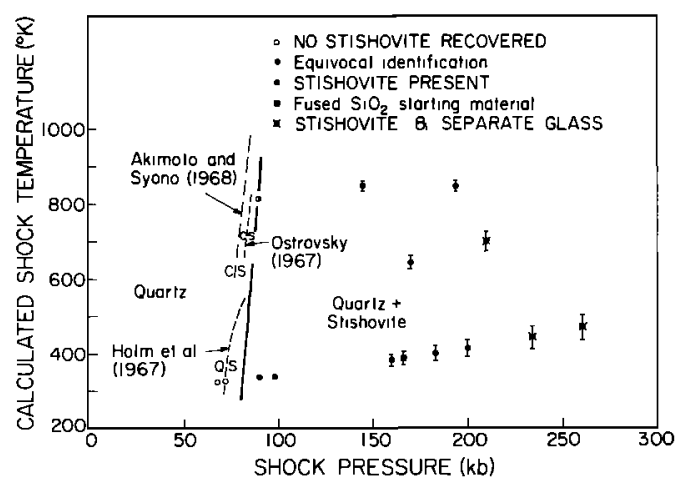

Fig. 3. Shock recovery products shown in relation to calculated shock temperature and shock pressure. 
were quenched immediately, so that reversion of stishovite to a SRO phase is unlikely. The inferred submicroscopic glass is therefore more likely the zero-pressure equivalent of a dense SRO phase, which is an essential part of an equilibrium assemblage involving shock-produced stishovite. The shot for which silica glass was the starting material produced by far the greatest yield of stishovite. It may well be that a dense SRO phase from which stishovite forms is more easily produced from silica glass.

Acknowledgments. This research was supported under NASA grant NGL-05-002-105. We appreciate the suggestions and helpful discussion offered by Taro Takahashi during the course of this study and criticism of the manuscript by Rex Gibbons.

\section{REFERENCES}

Ahrens, T. J., Shock melting and vaporization of metals, J. Appl. Phys., 49, 2443-2445, 1972.

Ahrens, T. J., and E. S. Gaffney, Dynamic compression of enstatite, J. Geophys. Res., 76, 5504$5513,1971$.

Ahrens, T. J., and V. G. Gregson, Jr., Shock compression of crustal rocks: Data for quartz, calcite, and plagioclase rocks, J. Geophys. Res., $69,4839-4873,1964$.

Ahrens, T. J., and J. T. Rosenberg, Shock metamorphism experiments on quartz and plagioclase, in Shock Metamorphism of Natural Materials, edited by B. M. French and N. M. Short, p. 59, Mono, Baltimore, Md., 1968.

Akimoto, S., and Y. Syono, The coesite-stishovite transition, in Accurate Characterization Of The High-Pressure Environment, Spec. Publ. 326, Nat. Bur. of Stand., Washington, D.C., 1971.

Chao, E. C. T., J. J. Fahey, and J. Littler, Stishovite, $\mathrm{SiO}_{2}$, a very high pressure new mineral from Meteor Crater, Arizona, J. Geophys. Res., 67, 419, 1962.

Chao, E. C. T., and J. Littler, Additional evidence for the impact origin of the Ries basin, Bavaria, Germany, Geol. Soc. Amer. Abst. for 1962, 127, 1963.

DéCarli, P. S., and D. J. Milton, Stishovite: Synthesis by shock wave, Science, 147, 144$145,1965$.

Gibbons, R. V., and T. J. Ahrens, Shock metamorphism of silicate glasses, J. Geophys. Res., $76,5489-5498,1971$.
Holm, J. L., O. J. Kleppa, and E. F. Westrum, Thermodynamics of polymorphic transformations in silica: Thermal properties from 5 to $1070^{\circ} \mathrm{K}$ and pressure-temperature stability fields for coesite and stishovite, Geochim. Cosmochim. Acta, 31, 2289, 1967.

Hörz, F., Statistical measurements of deformation structures and refractive indices in experimentally shock-loaded quartz, in Shock Metamorphism of Natural Materials, edited by B. M. French and N. M. Short, Mono, Baltimore, Md., 1968.

Kieffer, S. W., Shock metamorphism of the Coconino sandstone at Meteor Crater, Arizona, J. Geophys. Res., 76, 5449-5471, 1971.

Kleeman, J. D., Formation of diaplectic glass by experimental shock loading of orthoclase, $J$. Geophys. Res., 76, 5499-5503, 1971.

Linde, R. K., and D. N. Schmidt, Shock propagation in nonreactive porous solids, J. Appl. Phys., 87, 3259-3271, 1966.

McQueen, R. G., J. N. Fritz, and S. P. Marsh, On the equation of state of stishovite, J. Geophys. Res., 68, 2319, 1963.

McQueen, R. G., S. P. Marsh, J. W. Taylor, J. N. Fritz, and W. J. Carter, The equation of state of solids from shock wave studies, in High Velocity Impact Phenomena, edited by R. Kinslow, pp. 294-419, Academic, New York, 1970.

Ostrovsky, J. A., On some sources of errors in phase-equilibria investigations at ultra-high pressure, Geol. J., 5, 321, 1967.

Rice, M. H., R. G. McQueen, and J. M. Walsh, Compression of solids by strong shock waves, Solid State Physics, vol. 6, edited by F. Seitz and D. Turnbull, pp. 1-63, Academic, New York, 1958.

Robie, R. A., and D. R. Waldbaum, Thermodynamic properties of minerals and related substances at $298.15^{\circ} \mathrm{K}\left(25.0^{\circ} \mathrm{C}\right)$ and one atmosphere (1.013 bars) pressure and at higher temperatures, Geol. Surv. Bull., 1259, 1-256, 1968.

Stishov, S. M., and S. V. Popova, New dense polymorphic modification of silica, Geolehimiya, 10, 837-839, 1961.

Shipman, F. H., W. M. Isbell, and A. H. Jones, High-pressure Hugoniot measurements for several Nevada test site rocks, Final Rep. DASA 2214, General Motors Mater. and Structures Lab., Warren, Mich., 1969.

Skidmore, I. C., Introduction to shock waves in solids, Appl. Mater. Res., 4, 131, 1965.

Wackerle, J., Shock-wave compression of quartz, J. Appl. Phys., 33, 922-937, 1962.

(Received October 10, 1972; accepted May 1, 1973.) 